\title{
Research Categories, Priorities and Needs for Online Learning: A Delphi Study for Promote Excellence
}

\begin{abstract}
The main purpose of this paper is to identify and rank the future research categories, priorities and needs for online learning. Based on the main purpose of this study and the concerns, the key research inquiries are: 1) What are the major research categories identified by the online workers for online learning over the next ten years?; 2) What are the major research priorities identified by the online workers for online learning over the next ten years?; and 3) What are the major research needs identified by the online workers for online learning over the next ten years? This is a mixed study that utilizes both quantitative and qualitative data to provide detailed information to the researcher for the data collection. The Delphi Study was used to represent a constructive communication device among a group of experts. A total of 72 participants (24 female and 48 male) were selected and all of them completed all three rounds of the study. These experts identified top categories, priorities and needs for online learning. The author hopes that this study can find diverse resources, multicultural experiences, and egalitarian opportunities that open our minds and broaden our perspectives for online learning.
\end{abstract}

\section{Introduction}

To fortify online learner performances, there must be careful efforts to not only reform educational system but also support online learners with ready access to information that provide them with improving equal access opportunity to the system. Although majority of people define quality as largely synonymous with better test scores, this paper concentrates on in-dept attentions on the diverse aspects of online education quality. As mentioned by Frydenberg (2002), Bolliger and Martindale (2004), Jones (2003), Oblinger, Barone and Hawkins (2001), Oravec (2003), Roffe (2002), and Yang and Cornelious (2005), quality in online education is a multidimensional concept, which should encompass all the functions and activities of research about scholarship, academic programs, staffing, learners, buildings, facilities, equipment, services to the society and the academic milieus. This paper is aimed to accomplish in multifaceted efforts to improve online education policy and practice that support critical discussions of the criteria for evaluating the rigor and effectiveness of research that reflect the broadened perspective on practice. The critical issues of quality accreditation, the identification of qualifications and develop international policies for globalization can merge the interests of international public goods, the traditional public higher education sectors, the needs of online learners and the worldwide public interest (UNESCO, 2006).

Because today's world is complex and knowledge is developing fast, learning must go on throughout life. As noted by Williams (2003), not only youth but also adults should know how to deal with change that requires reformist actions in the quality of online education in all its aspects to accomplish excellence in learning. The main purpose of this research, therefore, is to identify the future research categories, priorities and needs of online education. In short, this paper aims to provide a rich 
collection of the ideas about understating the future trends of Online Learning and enriching the prospect analysis and practices in this area as a complex decision making process. The use of online learning will be different from the conservative implications developed in recent decades. Understanding the future research issues and challenges of these technologies can help online workers (online managers, communication designers, educational designers, tutors, mentors, support people, content providers, stakeholders, learners, parents, etc.) be more successful in their current professional roles.

\section{Purpose}

In the recent years, there has been a rapid movement on the powerfully utilization of the approaches, methods and techniques of online learning for converging social, societal and political problems in the near future. One of the major issues appearing perpetually throughout this concern is that of how to identify global values, norms and ethics which may find priorities of importance among diverse needs in the digital world (Green, 2002; Hine, 2003; Kirby, 1999; O'Sullivan, Morrell, \& O'Connor, 2002; Perrons, 2004). Therefore, establishing interactive online communication environments empowered by new communication technologies, designed to change our future virtual life is doing and what it undertakes to do, is one of the most complicated problems faced by online workers. As mentioned by Dhillon (2002), making right decisions to maintain and improve online workers' social responsibilities in the information age is important not only because of our increased dependence on new communication technologies, but because these technologies pose complex challenges, which will have a greater significance in the near future as well. In addressing major research priorities and needs as a way of scrutinizing the major research issues and challenges for online learning in the near future, these must be clearly identified and categorized as well as ranked on the basis of research and also on the online workers' values, norms and ethics toward the revolutionary communication technologies. The main purpose of this research, therefore, is to identify, categorize, and rank the future research needs and priorities of online learning. Based on the main purpose of this study and the concerns discussed above, these four research questions have been developed to prioritize the goals and directions:

1. What are the major research issues and challenges identified by the online workers for online learning over the next ten years?

2. What are the major research categories identified by the online workers for online learning over the next ten years?

3. What are the major research priorities identified by the online workers for online learning over the next ten years?

4. What are the major research needs identified by the online workers for online learning over the next ten years?

In short, this paper aims to provide a rich collection of the online workers' ideas about projecting the future trends of online learning and enriching the prospect analysis and practices in this area as a complex decision making process. The use of online learning will be different from the conservative implications developed in recent decades. Understanding the future research priorities and needs of these 
technologies can help online workers be more successful in their current professional roles.

\section{Theoretical Framework}

Understanding the categories, priorities and needs of online education can help researchers understand how to manage their role tasks, give careful attentions to diverse online community (Doolittle, 2006; Perrons, 2004). Besides, they can understand their important roles and responsibilities how to establish global values, norms and ethics by utilizing new communication technologies. Therefore, this article is combined the Media Richness Theory and Constructivist Theory together as a theoretical and philosophical foundation. These theories can help the researcher design the research survey based on a mixed research method. Regardless of socioeconomic and cultural contexts, the theoretical framework of this paper help the researcher recreate, renovate and modified online education, which follows novel movements in online education. The policies and strategies of advanced research can make available data and analysis of the research missions in online education that the current research function can be analyzed and modifications considered ascertaining online education quality, which is indispensable to confirm the importance of research development to ensure equitable socio-economic and cultural progress for all learners. Due to increased cultural sensitivity and pressure for egalitarianism, therefore, research should specifically emphasize on sharing inventive experiences in online education which serve as examples of high-quality practice in multicultural circumstances.

This constructivist learning milieu combined with the principles and strategies of the Media Richness Theory (Daft and Lengel, 1986; Daft, Lengel and Trevino, 1987), which helped the course owner concentrate on significantly decreasing the boundaries of time and space. The media richness of a channel was concerned about examining the four main aspects of online synchronous communications:

1. the capacity for immediate feedback determined by the amount and the promptness of the feedback the receiver could give to the sender;

2. the ability to support natural language regarded to have the ability to support natural language if the sender could structure and send the message in the most intuitive manner or as if it were in a conversation;

3. the number of cues was provided by the channel included both verbal and non-verbal cues such as tone of voice, hesitation, facial expressions, vocal cues, dress and posture.

As underlined by McChesney (1999), these issues helped the learners to interact more effectively and the extent to which the channel generated social presence for the receiver provided by a channel influences individuals' motivation to engage in interpersonal communication. Furthermore, online learners could appraise the quality of online learning whereas they decreased ambiguity about authentic practices. In this context, empowering virtual communications through the proper selections of new media can improve critical thinking skills based on the core of constructivist learning process that this interactive milieu would help these learners develop more positive attitudes toward online learners. 


\section{Method}

This is a mixed study that aims to identify, and rank the future research categories, priorities and needs for online learning over the next ten years from the complex problems of people and natural sources. For these reasons, this research utilized both qualitative and quantitative data to provide the information in detail to the researcher for the data collection. This research was conducted totally online during the 2005-2006 school year. The researcher sent an email messages to the different professional listservs to both introduce her study and ask the digital people whether they would like to participate this research voluntarily. Although there were volunteer 110 participants after the first call, 38 of them chose not to participate in this study. They were excluded from the research study with no penalty. The researcher assembled an online panel of 72 participants (24 female and 48 male) from across the world and including online administers, online communication designers, online content providers, online learners, online support staff from the broad area of Open and Distance Education.

This Decision Delphi Study begun with a questionnaire designed by the researcher, and the survey was posted on a secure Internet Website to a small team and a larger group of experts. At the end of the survey, a series of questions seeking feedback about the survey was posted. After the questionnaire was returned, the researcher summarized the results. The evaluative portion was asked for specific feedback about survey content and layout, as well as addressing issues of categories, priorities and needs of online learning. At the end of the evaluation form, a question was added asking if there was anything else they would like to address. Participants were advised to visit the Website and complete the survey and the evaluation form. They were allowed to complete the survey on the Website. The experts were allowed the opportunity to change their responses based on the results, and these second-round and third-round results were reevaluated by the researcher. This process continued until consensus was reached and also it would become clear that no consensus is possible. Both qualitative and quantitative questions asked the experts and the information was then analyzed and feed back to each person, via further questions, and their responses were analyzed and fed back, and so on, until the goal was reached, that was when a consensus was reached which offered synthesis and clarity on the question. In this study, methodically facilitating the online communications took place via several stages of the researcher asking questions, undertaking analysis, and providing feedback.

\section{Research Setting and Participants}

This research was conducted completely online during the 2005-2006 school year. The researcher sent email messages to the different professional listservs to both introduce her study and ask the digital people whether they would like to participate in this research voluntarily. 110 participants volunteered after the first call, 38 of them chose not to participate in this study. They were excluded from the research study with no penalty. The researcher assembled an online panel of 72 online workers (24 female and 48 male) from across the world and including online administrators, online communication designers, online content providers, online learners, online support staff from the broad area of Open and Distance Education. A total of 72 participants were selected and all of them completed all three rounds of the study. 
These expert panelists identified top research issues and challenges, categorize, priorities and needs of the future researches for information dissemination and partnership development between online workers. After the data were collected from the Delphi study, strategic planning around the identified research main concerns resulted in a planning document to ensure ongoing needs and priorities of research with online workers to the year 2016.

Table 1 shows that there were three female online administrators whereas there were seven female online content providers in this study. These online administrators were senior professionals in distance education area. Of six female online communication designers, the five of them (83.3\%) had at most five year experiences in their professional area. Of 24 female participants, the four of them (16.6\%) were either freshman or sophomore learners at the different Colleges. There were only three female online support staff, who were junior online workers whereas there were no senior female online support staff.

Table 1

The Backgrounds of the Female Participants

\begin{tabular}{|c|c|c|c|c|c|c|c|c|c|c|c|c|c|c|c|c|c|c|c|c|}
\hline \multirow{2}{*}{$\begin{array}{r}\text { The } \\
\text { Professional } \\
\text { Area in } \\
\text { Distance } \\
\text { Education }\end{array}$} & \multicolumn{8}{|c|}{$\begin{array}{c}\text { Online } \\
\text { Communication } \\
\text { Designers }\end{array}$} & \multicolumn{4}{|c|}{$\begin{array}{c}\text { Online } \\
\text { Content } \\
\text { Providers }\end{array}$} & \multicolumn{4}{|c|}{$\begin{array}{c}\text { Online } \\
\text { Learners }\end{array}$} & \multicolumn{4}{|c|}{$\begin{array}{l}\text { Online } \\
\text { Support } \\
\text { Staff }\end{array}$} \\
\hline & 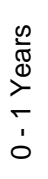 & 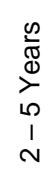 & 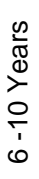 & 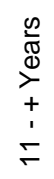 & 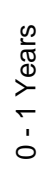 & 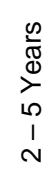 & 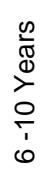 & 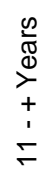 & 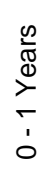 & 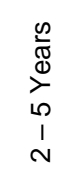 & 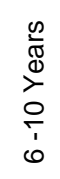 & 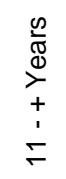 & 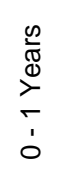 & 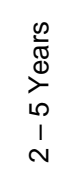 & 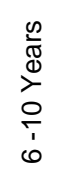 & 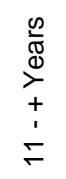 & 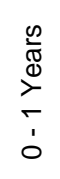 & 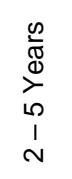 & 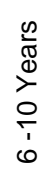 & 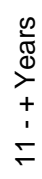 \\
\hline Female & - & - & 2 & 1 & 2 & 3 & 1 & - & - & 1 & 2 & 4 & 2 & 2 & - & - & 2 & 1 & - & - \\
\hline Sub-Total 1 & & & & & & & & & & 1 & & 6 & 4 & 4 & - & & 3 & & 1 & \\
\hline Sub-Total 2 & \multicolumn{4}{|c|}{$\checkmark$} & \multicolumn{4}{|c|}{6} & \multicolumn{4}{|c|}{7} & \multicolumn{4}{|c|}{4} & \multicolumn{4}{|c|}{4} \\
\hline
\end{tabular}

Table 2 indicates that there were totally six male online administrators whereas there were 11 male online communication designers in this study. These online administrators were senior professionals in distance education area. Of 12 male online content providers, the five of them (41.7\%) had at most five year experiences in their professional area whereas the rest of them had six or more than six year experiences. Of 48 male participants, the 10 of them (20.8\%) were either junior or senior online support staff. All participants were asked individually to read and sign the online informed consents form, which described the research in detail. Therefore, they participated voluntarily in this research. 
Table 2

The Backgrounds of the Male Participants

\begin{tabular}{|c|c|c|c|c|c|c|c|c|c|c|c|c|c|c|c|c|c|c|c|c|}
\hline \multirow{2}{*}{$\begin{array}{r}\text { The } \\
\text { Professional } \\
\text { Area in } \\
\text { Distance } \\
\text { Education } \\
\text { Gender }\end{array}$} & \multicolumn{8}{|c|}{$\begin{array}{c}\text { Online } \\
\text { Communication } \\
\text { Designers }\end{array}$} & \multicolumn{4}{|c|}{$\begin{array}{c}\text { Online } \\
\text { Content } \\
\text { Providers }\end{array}$} & \multicolumn{4}{|c|}{$\begin{array}{c}\text { Online } \\
\text { Learners }\end{array}$} & \multicolumn{4}{|c|}{$\begin{array}{l}\text { Online } \\
\text { Support } \\
\text { Staff }\end{array}$} \\
\hline & 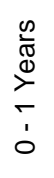 & 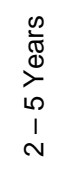 & 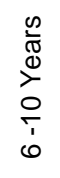 & 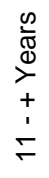 & 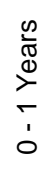 & 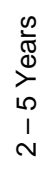 & 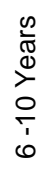 & 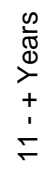 & 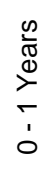 & 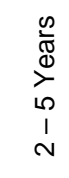 & 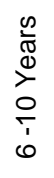 & 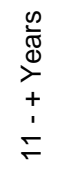 & 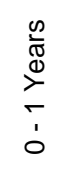 & 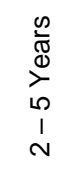 & 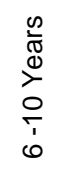 & 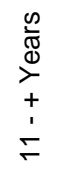 & 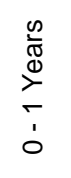 & 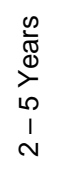 & 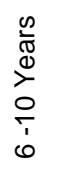 & $\begin{array}{l}\stackrel{n}{\tilde{\sigma}} \\
\stackrel{0}{\nu} \\
+ \\
+ \\
-1 \\
-1\end{array}$ \\
\hline Male & - & 1 & 3 & 2 & 2 & 6 & 2 & 1 & 2 & 3 & 2 & 5 & 3 & 3 & 1 & 2 & 2 & 3 & 4 & 1 \\
\hline Sub-Total 1 & & L & & & & & & & & 5 & & 7 & 6 & 6 & 3 & & 5 & & 5 & \\
\hline Sub-Total 2 & \multicolumn{4}{|c|}{6} & \multicolumn{4}{|c|}{11} & \multicolumn{4}{|c|}{12} & \multicolumn{4}{|c|}{9} & \multicolumn{4}{|c|}{10} \\
\hline TOTAL & \multicolumn{20}{|c|}{48} \\
\hline
\end{tabular}

\section{Data Sources}

This Decision Delphi Study began with a questionnaire designed by the researcher, and the survey was posted on a secure Internet Website to a small team and a larger group of experts. At the end of the survey, a series of questions seeking feedback about the survey was posted. After the questionnaire was returned, the researcher summarized the results. The evaluative portion was asked for specific feedback about survey content and layout, as well as addressing issues of issues and concerns, categories, priorities and needs of online learning. At the end of the evaluation form, a question was added asking if there was anything else they would like to address. Participants were advised to visit the Website and complete the survey and the evaluation form. They were allowed to complete the survey on the Website. The experts were allowed the opportunity to change their responses based on the results, and these second-round and third-round results were revaluated by the researcher. This process continued until consensus was reached and also it would become clear that no consensus is possible.

A Delphi Study was designed to develop the instrument for the Online Learning survey. The incorporation of the Delphi method in the Internet milieu makes possible a number of significant refinements of the priorities and needs to the nature of online learning. The Delphi method was used to take advantage of the judgments of a group of experts for the purpose of making decisions, determining needs and priorities, and also making predictions. It provided an opportunity to obtain diverse opinions from a wide variety of experts across the world. Besides, the Delphi method allowed each expert to share her/his opinion, without being pressured by others in the group. The survey data was grouped according to the four sub-research questions:

1. the major research issues and challenges;

2. the major research categories;

3. the major research priorities; and

4. the major research need.

As noted by Osborne, Ratcliffe, Collins, Millar and Duschl (2000), the number of rounds for a Delphi Study will be determined by how efficiently the panel reaches consensus. On the other hand, many Delphi studies confine themselves to three 
rounds due to pragmatic reasons. For such reasons of time, therefore, a three-round Decision Delphi application was chosen to determine the extent to which consensus exists among experts within the distance education community about the future research priorities and needs of online learning.

\section{Data Analysis}

This Delphi Study process essentially provided an interactive communication structure between the researcher and experts in the distance education in order to identify, categorize and rank the future research needs and priorities for online learning. Both qualitative and quantitative questions asked the experts and the information was then analyzed and feed back to each person, via further questions, and their responses were analyzed again recycled for feed back, and so on, until the goal was reached, that was when a consensus was reached which offered synthesis and clarity on the question. As noted by Rockwell, Furgason and Marx (2000) and Osborne, Ratcliffe, Collins, Millar and Duschl (2000), each step of this three-round Decision Delphi Study is described below:

In the first round of Delphi panel, the items were rated from very important to very unimportant. The first round instrument was posted on a World Wide Web page. All of the panel participants accessed and answered the questionnaire electronically. Seventy-two panel members participated in the first round. In the second round of Delphi panel, mean scores were calculated for each item from the first Delphi Panel response using a five-point scale (very important $=1$; important $=2$; neither important or unimportant $=3$; unimportant $=4$; and very unimportant $=5$ ). For the Delphi panel's second instrument, the mean score was marked on an importance scale for each of the original items; panel members were then asked to rate the accuracy of the mean scores using a three-point scale comprised of should reflect More Importance, is an Accurate representation of importance and should reflect Less Importance. From the comments written in on the first round, eight new items were added to the second round questionnaire. Respondents were asked to rate the importance of these items using the same five-point scale employed in the first round instrument. Seventy-two panel members completed the second round instrument. Finally, in the last round of the Delphi Study, frequency distributions were calculated for the accuracy ratings given to each of the original items. The mean scores of the second round were adjusted based on the net difference between the proportions of responses, demonstrating the item was judged either more important or less important. The adjusted means were added to the instrument for a third round. The third round instrument again asked for a rating of the accuracy of the mean scores using a three-point scale (should reflect More Importance, is an Accurate representation of importance and should reflect Less Importance). In this study, methodically facilitating the online communications took place via several stages of the researcher asking questions, undertaking analysis, and providing feedback.

Three faculty, who were experts in distance education, coded the participants' responds in the reliability check process. Therefore, this Decision Delphi study process, as a recognized research technique, helped to strengthen the validity of the results considerably. As mentioned by Patton (1990) and Turoff and Hiltz (1996), the anonymous and iterative nature of this process allowed the participants to submit 
their diverse opinions and make their critical decisions without meeting in person. Finally, this Decision Delphi application can be broadly used to generate forecasts in Online learning(Cornish, 1977), and to empower expeditious understanding about the future consequences of present choices (Amara and Salanik, 1972). In this study, the forecasting was a probabilistic, reasonably definite statement about the future based on an evaluation of alternative possibilities, and included "...all efforts to project technological capabilities and to predict the invention and spread of technological innovations..." (Ascher, 1979, p. 165).

\section{Findings and Discussions}

The present study focused on identifying and ranking the future research categories, priorities and needs for online learning that enhance the relevance of education by adjusting learning processes, multicultural curriculum contents and egalitarian program management, and discuss the major research issues and challenges of online learning and measure its quality. Empowering online learning can have significantly positive impacts on design quality that effects of participant deception can be mitigated by employing a critical pedagogy approach. Online learning can be designed related to the potentials and impacts of diverse communications that provide background knowledge needed to understand the interaction processes related to democratic issues.

The major research categories were those that help define important and urgent research areas in online learning (Table 3). Online workers emphasized that focusing on global democratic citizenships could respect online human rights and social identities by measuring how to build online accountable management systems under a framework with suitable capacity-building to make critical decisions and construct powerful action plans. Quality in online learning was a multidimensional concept, which encompassed all the functions and activities of research about learners, scholarship, academic programs, staffing, service facilities, equipment, etc. to the society and the academic milieus. In this case, there were three main areas, which triggered curriculum change:

1. the professional developments of online institutes;

2. the qualifications and performances of online workers; and

3. the new media adoption strategies and policies.

To conduct high-quality educational education, online professionals should establish global values and criteria of evaluation process, the research participants pointed out that accreditation could provide online professionals with comprehensive strategies to planning and conducting educational evaluation process. Besides, these accreditation activities covered the constructivists' viewpoints, concepts and issues of online education on how build scientifically sound educational evaluation to ascertain the quality of online education.

Online workers highlighted that the major research priorities underlined the necessary improvements, and promoting intellectual and scientific collaborations of online workers training, curriculum developments and learning environment designs that empowered online learning and communicational activities with regard to considering the global societal values (Table 4). Therefore, online learning will play 
Table 3

The Major Research Categories for Online Learning

How important is it to

Very Important $\left(=1.000\right.$ to $\left.1.499^{\mathrm{a}}\right)$

1.052 online learners

1.128 global online democratic citizenships

1.136 online human rights

1.189 online social identities

1.201 online accountable management systems

1.261 suitable capacity-building

1.277 critical decisions

1.296 action plans

1.367 professional developments

1.379 qualifications and performances

1.458 new media adoption

1.482 global values and criteria for evaluation process

1.492 accreditation activities

Quite Important ( $=1.500$ to $1.999^{\mathrm{a}}$ )

1.792 scholarship

1.814 academic programs

1.837 support staff

1.946 service facilities

Somewhat Important $\left(=2.000\right.$ to $\left.2.499^{\mathrm{a}}\right)$

2.178 equipment

2.359 online institutes

Neither Important Nor Unimportant $\left.\mathrm{C}=2.500-2.999^{\mathrm{a}}\right)$

2.816 internal institutional trends

a Scale: $\mathbf{1}=$ Very important $\mathbf{2}=$ Important $\mathbf{3}=$ Neither important nor unimportant $\mathbf{4}=$ Unimportant $\mathbf{5}=$ Very unimportant

varied and complex roles in developing education programs that reorganize their higher education systems and structures that have been strongly interested in integrating new communication technologies to generate democratic learning milieus from the different domains, including politics, online learners, the faculty, universities, science, societies technology, industry, and business. Online learning will contribute to the powerful integration of new media regard to the result of scientific research in the process of global development and the current significance of higher education, which answer to authentic societal needs that innovate in their interdisciplinary online curriculums and programs for not only lifelong learning and the qualitative revolution, but also accreditation and evaluation. Becoming more open, innovative and flexible can adjust with societal trends and requirements online education, which indicates the highly complex procedure involved in critical curriculum development including the different approaches of action in international collaborations to raise quality of online education. 
Table 4

The Major Research Priorities for Online Learning

How important is it to

Very Important $\left(=1.000\right.$ to $1.499^{\mathrm{a}}$ )

1.157 promote intellectual interactions

1.289 empower scientific collaborations

1.306 support online learning

1.378 encourage communicational activities

1.397 consider global societal values

1.425 define complex roles

1.469 reorganize higher education systems

1.484 integrate new communication technologies

Quite Important $\left(=1.500\right.$ to $\left.1.999^{\mathrm{a}}\right)$

1.517 generate democratic learning milieus

1.797 include different domains

1.813 contribute new media integration

1.896 answer authentic societal needs

Somewhat Important $\left(=2.000\right.$ to $2.499^{\mathrm{a}}$ )

2.123 innovate in interdisciplinary online curriculums

2.129 adjust societal trends and requirements

2.356 involve in a critical curriculum development

Neither Important Nor Unimportant $\left.\mathrm{C}=2.500-2.999^{\mathrm{a}}\right)$

2.682 indicate highly complex procedure

2.715 include different actions in international collaborations

a Scale: $\mathbf{1}=$ Very important $\mathbf{2}=$ Important $\mathbf{3}=$ Neither important nor unimportant $\mathbf{4}=$ Unimportant $\mathbf{5}=$ Very unimportant

Online workers underlined that the major research needs utilize the advantages and potential of advanced communication technologies by guaranteeing quality and sustaining high standards for education practices and outcomes, ensuring online education facilities based on local, national and global networks, and increasing online education efficiency and preserving its quality and significance (Table 5). The online workers pointed out that producing detailed description and develop possible explanations of a necessary research agenda could evaluate online programs efficiently. This could provide them with diverse information on guidelines related to multicultural providers of online education on the identification of qualifications including updates and critical activities and concerning the challenges of globalization on the evaluation process in quality assurance and accreditation (Bonk, 2001).

Online learning, therefore, will impact better online education developments in different universities from the globe. Online learning must have activist communications, which focus on authentic experiences in critical dialogues. Online communication workers, therefore, are inspired to develop culturally responsive, social justice-oriented, critical and creative communication plans that go beyond power elites' mandates. 
Table 5

The Major Research Needs for Online Learning

How important is it to

Very Important ( $=1.000$ to $\left.1.499^{\mathrm{a}}\right)$

1.104 utilize the advantages of advanced communication technologies

1.357 adapt advanced communication technologies

1.365 guarantee quality for education practices

1.381 sustain high standards for outcomes

1.391 ensure online education facilities

1.417 increase online education efficiency

1.454 preserve quality and significance

1.483 produce detailed description for a necessary research agenda

Quite Important $\left(=1.500\right.$ to $1.999^{\mathrm{a}}$ )

1.513 develop possible explanations

1.735 evaluate online programs efficiently

1.778 provide diverse information on guidelines related to multicultural providers

1.811 identify qualifications including updates and critical activities

1.854 concern the challenges of globalization on the evaluation process

1.867 focus on quality assurance and accreditation

1.982 have activist communication

1.987 focus on authentic experiences in critical dialogues

Somewhat Important $\left(=2.000\right.$ to $\left.2.499^{\mathrm{a}}\right)$

2.345 develop culturally responsive communication plans

2.373 improve social justice-oriented critical communications

2.386 go beyond power elites' mandates

Neither Important Nor Unimportant $\left(=2.500-2.999^{\mathrm{a}}\right)$

2.814 facilitate for informal online communications

a Scale: $\mathbf{1}=$ Very important $\mathbf{2}=$ Important $\mathbf{3}=$ Neither important nor unimportant $\mathbf{4}=$ Unimportant $\mathbf{5}=$ Very unimportant

\section{Conclusion}

There exists a common consensus on the authenticity of advancing research that promotes research in online education. These online education institutions should give urgent priority to dealing with research measuring quality, increasing the relevance of online education, quality for everyone, reforming the online education system, and better teaching and learning systems. This paper makes first-level assessments about the credibility, viability and quality of either current or prospective online education programs by providing fundamental inquires for critical reflections. As noted by Bonk, Kim, and Zeng, (2006), Howell, William and Lindsay (2003), and Paulson (2002), a better understanding and measurement of quality of online learning in the diverse contexts provides disadvantage individuals with quality 
education opportunities attention to address their needs as well. This research provides information in detail information about online programs, which aim to make sure that education presents ideas and values about building a sustainable future, give learners the chance and learn about the global world. This can be build in-depth respect for diversity and differences (Bolam and Dodgson, 2003; Ketterer and Marsh, 2006; Rovai, 2003). This article, moreover, can help online workers to rethink online education by focusing on the more pressing educational and social problems of our time, and also understand the achievement challenges and assessment concerns of lifelong learning. Finally, this paper can provide lifelong learners with pedagogical knowledge and design guidelines for the online education-oriented design in a multicultural view.

As mentioned by Oakley (2004) and O'Sullivan, Morrell, and O'Connor (2002), future researches assist with a range of issues in higher education, such as academic mobility, international exchanges of excellence, knowledge production, curriculum innovation, leadership roles, and the defense of quality in online learning qualifications. These activities can provide well-built proposals for knowledge exchanges on quality assurance and accreditation as well as the identification of qualifications. To extend the understanding of online systems, structures, policies, trends and developments, a research guideline can connect with existing and ongoing research; make visible invisible research gaps; encourage interdisciplinary research; bring to the current issues and debates together; make available research findings; deliver information on policies; facilitate multicultural research practices; encourage systematic operational researches; and investigate research policy.

\section{References}

Bolam, H., \& Dodgson, R. (2003). Retaining and supporting mature students in higher education. Journal of Adult and Continuing Education, 8(2), 179-194.

Bolliger, D.U., \& Martindale, T. (2004). Key factors for determining student satisfaction in online courses. International Journal on E-Learning, 3(1), 61-7.

Bonk, C.J., Kim, K.J., \& Zeng, T. (2006). Future directions of blended learning in higher education and workplace learning settings. In C.J. Bonk and C.R. Graham (Eds.). Handbook of Blended Learning: Global Perspectives, Local Designs (pp. 550-568). San Francisco, CA: Pfeiffer Publishing. [Online] Available: http://php.indiana.edu/ cjbonk/c083_bonk_future.pdf

Doolittle, P.E. (2006). Constructivism and Online Education. Retrieved April 04, 2006, from http://edpsychserver.ed.vt.edu/workshops/tohe1999/text/doo2.doc

Frydenberg, J. (2002). Quality standards in e-Learning: A matrix of analysis. International Review of Research in Open and Distance Learning, 3(2). Retrieved February 04, 2006, from http://www.irrodl.org/index.php/irrodl/article/view/109/189 
Howell, S.L., William, P.B., \& Lindsay, N.K. (2003). Thirty-two trends affecting distance education: an informed foundation for strategic planning. Online Journal of Distance Learning Administration, 6(3). Retrieved June 25, 2006, from http://www.westga.edu/ distance/ojdla/fall63/howell63.html

Jones, R. (2003). A recommendation for managing the predicted growth in college enrollment at a time of adverse economic conditions. Online Journal of Distance Learning, Administration (6)1. Retrieved April 04, 2006, from http://www.westga.edu/\%7Edistance/ojdla/spring61/jones61.htm

Ketterer, J.J., \& Marsh, G.E. (2006). Re-conceptualizing intimacy and distance in instructional models. Online Journal of Distance Learning Administration, 9(1). Retrieved March 08, 2006, from http://www.westga.edu/\%7Edistance/ojdla/spring91/ketterer91.htm

McChesney, R. W. (1999). Rich Media, Poor Democracy: Communication Politics in Dubious Times. Illinois: University of Illinois.

Oblinger, D., Barone, C.A., \& Hawkins, B.L. (2001) Distributed education and its challenges: An overview. American Council on Education (ACE). Retrieved April 04, 2006, from http://www.acenet.edu/bookstore/pdf/distributedlearning/distributed-learning-01.pdf

Oakley, B. II. (2004). The value of online learning: Perspectives from the University of Illinois at Springfield. Journal of Asynchronous Learning Networks, 8(3), 22-32.

Oravec, J. (2003). Some influences of online distance learning on US higher education. Journal of Further and Higher Education, 27(1), 89-104.

O'Sullivan, E., Morrell, A., \& O'Connor, M.A. (2002). Expanding the Boundaries of Transformative Learning. New York, NY: Palgrave.

Paulson, K. (2002). Reconfiguring faculty roles for virtual settings. The Journal of Higher Education. 73(1), 123-140.

Perrons, D. (2004). Globalization and Social Change: People and Places in a Divided World. New York, NY: Routledge.

Roffe, I. (2002). E-Learning, engagement, enhancement and execution. Quality Assurance in Education, 10(1), 40-50.

Rovai, A.P. (2003). A practical framework for evaluating online distance education programs. Internet and Higher Education, 6(2), 109-124.

UNESCO (2006). Education University Quality and Mobility. Retrieved July 12, 2006, from

http://portal.unesco.org/education/admin/ev.php?URL_ID=21670\&URL_DO=D O_TOPIC\&URL_SECTION=201 
Williams, P.E. (2003). Roles and competencies for distance education programs in higher education institutions. The American Journal of Distance Education, 17(1), 45-57.

Yang, Y., \& Cornelious, L.F. (2005). Preparing instructors for quality online instruction. Online Journal of Distance Learning Administration, 8(1). Retrieved October 08 , 2005, from http://www.westga.edu/ distance/ojdla/spring81/yang81.htm 